\title{
Patterns of Adverse Childhood Experiences and Their Influences on Depressive Symptoms, Difficulty in Emotion Regulation, and Interpersonal Maladjustment
}

\author{
Aely Park ${ }^{1}$, Ick-Joong Chung ${ }^{2}$ \\ Research Professor, Department of Social Welfare, Ewha Womans University, Seoul, Korea ${ }^{1}$ \\ Professor, Department of Social Welfare, Ewha Womans University, Seoul, Korea ${ }^{2}$ \\ 아동기 부정적 생애경험의 잠재적 유형화: 우울, 정서조절의 어려움 및 \\ 대인관계 부적응과 유형화간의 관계 \\ 박애리 ${ }^{1}$, 정익중 ${ }^{2}$ \\ 이화여자대학교 사회복지학과 연구교수 ${ }^{1}$, 이화여자대학교 사회복지학과 교수 ${ }^{2}$
}

Objectives: The study aimed to identify patterns of adverse childhood experiences (ACE) and to investigate how different patterns of ACE influence depressive symptoms, difficulty in emotion regulation, and interpersonal maladjustment.

Methods: This study utilized 1,033 adults (ages 18-64 years) who participated in the Korean General Social Survey. Latent Class Analyses (LCA) were employed to identify homogeneous groups of adults with similar patterns of ACE. Multiple linear models were used to examine the relationships between ACE classes and the three adult outcomes of depressive symptoms, difficulty in emotion regulation, and interpersonal maladjustment.

Results: LCA results indicated that three classes fit the data best across the sample and were labeled 'Low ACE Group (61\%)', 'Child Maltreatment Group (20\%)', and 'Family Violence and Child Maltreatment Group (19\%)'. Regression analysis controlling for age, gender, monthly average household income, and educational level indicated that compared with adults in the Low ACE Group, adults in the Child Maltreatment Group and the Family Violence and Child Maltreatment Group reported more depressive symptoms, more difficulty in emotion regulation, and higher interpersonal maladjustment.

Conclusions: Adults who have multiple ACE can be more susceptible to mental health problems during adulthood.

Keywords: Adverse Childhood Experiences (ACE), child maltreatment, depressive symptoms, latent class analysis

\section{Introduction}

아동기 부정적 생애경험(Adverse Childhood Experiences [ACE])

Corresponding Author: Ick-Joong Chung, Professor, Department of Social Welfare, Ewha Womans University, 52, Ewhayeodae-gil, Seodaemun-gu, Seoul, Korea

E-mail: ichung@ewha.ac.kr
은 성인기 이전에 학대와 방임뿐만 아니라 가정폭력, 가구원 중 우울, 음주 또는 약물 사용 등 가족기능 장애로 인해 겪게 되는 여러 부정적 경험들을 포괄하는 개념이다(Felitti, 2002;

(C)The Korean Association of Child Studies

This is an Open Access article distributed under the terms of the Creative Commons Attribution Non-Commercial License (http:// creativecommons.org/licenses/by-nc/4.0) which permits unrestricted noncommercial use, distribution, and reproduction in any medium, provided the original work is properly cited. 
Ryu, Lee, Jung, Song, \& Lee, 2017; World Health Organization [WHO], 2009). 'National Survey of Children's Exposure to Violence (NatSCEV)'에 따르면, 2008년 미국의 18 세 미만의 아 동 중 약 $66 \%$ 가 한 가지 이상의 $\mathrm{ACE}$ 에 노출되었고, $30 \%$ 이 상이 5 가지 혹은 그 이상, 그리고 약 $10 \%$ 가 10 가지를 경험하 는 것으로 나타났으며(Turner, Finkelhor, \& Ormrod, 2010), 좀 더 최근에 '2016 National Survey of Children's Health (NSCH)' 는 미국의 약 $45 \%$ 의 아동이 적어도 한 가지 이상의 $\mathrm{ACE}$ 에 노 출됐다고 발표함에 따라(Sack \& Murphey, 2018), 여전히 절반 에 가까운 아동들이 $\mathrm{ACE}$ 에 고통 받고 있는 것으로 조사됐다. 한국의 경우, 신체적, 정서적, 방임과 같은 아동학대 발생률은 '아동학대 실태조사'와 같은 몇몇 조사를 통해 이뤼졌으나, 생 애과정에 장기적이고 부정적인 영향을 미치는 아동기 경험을 $\mathrm{ACE}$ 와 같이 폭넓은 관점에서 그 발생률을 다루는 조사는 매 우 드물다. 소수의 연구가 ACE 현황을 다루고 있는데, 예를 들 어, 한국보건사회연구원의 Ryu 등(2017)은 '아동가족 생애경 험 실태조사'를 통해 18 세 미만의 자녀를 둔 성인 부모의 약 $79 \%$ 가 ACE에 노출되었고, Song과 Lee (2016)는 '한국종합사 회조사'를 통해 성인의 약 $57 \%$ 가 한 가지 이상의 ACE가 있었 다고 보고하였다. 이 두 조사를 통해보면, 한국에서 아동학대 이상으로 $\mathrm{ACE}$ 발생이 상당히 높게 나타나고 있는 것을 알 수 있다(Ryu et al., 2017).

$\mathrm{ACE}$ 는 원래 아동기의 부정적 경험이 이후의 성인건강에 영향을 미치는지의 여부와 미친다면 어떻게 영향을 미치는지 에 관심을 가졌던 미국의 질병통제센터(the Centers for Disease Control [CDC])와 Kaiser Health Plan in San Diego, California가 17,000 여명의 건강보험에 가입된 성인을 대상으로 실시한 연 구로부터 시작되었다. 관련 연구들을 통해 아동기의 외상적 경험들이 시간을 통해 해소되기 보다는 오히려 성인기 신체와 정신건강에 부정적인 영향을 미친다는 연구결과(e.g., Anda et al., 2002; Dong, Dube, Felitti, Giles, \& Anda, 2003; Dube et al., 2001; Felitti et al., 1998)들이 발표되면서 생애과정에서 나타나 는 건강문제 개선을 위해 아동기 삶의 조건들을 향상시키는 것이 중요한 과제임이 강조되었다(Braveman \& Barclay, 2009).

지금까지 서구의 여러 연구들이 $\mathrm{ACE}$ 노출이 성인기의 우울증 및 자살시도의 위험을 높이고(e.g., Bellis et al., 2014; Campbell, Walker, \& Egede, 2016; Shin, McDonald, \& Conley, 2018), 알코올에 따른 문제 및 약물사용에 영향을 미치며(e.g., Anda et al., 2006; Ford, Butler, Hughes, Quigg, \& Bellis, 2016; Mersky, Topitzes, \& Reynolds, 2013), 당뇨와 암 등의 신체질환 발병률(Bellis et al., 2015; Felitti et al., 1998)과 관계가 있다고 보
고하였다. 이처럼 성인 건강에 장기적이며 광범위하게 미치는 부정적인 영향으로 인해 $\mathrm{WHO}$ 에서는 $\mathrm{ACE}$ 를 막대한 사회적 비용을 야기하는 사회문제로 규정하고 이에 대한 예방과 개입 을 필수적인 사회정책으로 제시하고 있다(M. H. Lee \& Kim, 2017). 2009년 WHO와 CDC가 주도한 'ACE 글로벌 연구네트 워크 프로젝트'에 서구뿐만 아니라 사우디아라비아 및 중국과 베트남 등의 아시아 국가들이 참여하면서, 이들 국가에서 $\mathrm{ACE}$ 의 장기적 효과와 그 결과에 대한 이해를 위해 그리고 ACE 발 생을 감시(global surveilance of ACE)하기 위한 노력이 진행되었 다(S. Kim \& Kim, 2017). 이의 일환으로 ACE 발생률과 그 효 과에 관한 연구들이 수행되었다. 예를 들어, 필리핀 성인의 약 $75 \%$ 가 ACE에 노출되었고(Ramiro, Madrid, \& Brown, 2010), 중 국의 경우, 연구 참여자의 약 $68 \%$ 가 $\mathrm{ACE}$ 에 노출되었고, 다양 한 $\mathrm{ACE}$ 에 노출될수록 더 많은 알코올 관련 문제행동을 보인 다고 밝혔다(Xiao, Dong, Yao, Li, \& Ye, 2008). 사우디아라비아 의 경우는 연구 참여자의 약 $82 \%$ 가 $\mathrm{ACE}$ 에 노출됨과 동시에, 약 $32 \%$ 의 성인이 4 개 이상의 $\mathrm{ACE}$ 에 노출되었으며, 성인기에 우울과 불안 및 약물사용이 높게 나타났다(Almuneef, Qayad, Aleissa, \& Albuhairan, 2014). 따라서, 사우디아라비아를 포함한 아시아 여러 나라에 있어서도 ACE의 발생률이 상당히 높으며, 그 영향력 또한 광범위하고 부정적인 것을 알 수 있다.

이러한 해외의 활발한 연구와 관심에도 불구하고, 한국에 서는 $\mathrm{ACE}$ 에 대한 경험적 연구가 매우 부족한 실정이다. 아직 까지 한국에서 아동기 부정적 경험에 대해 $\mathrm{ACE}$ 보다는 아동 학대와 방임과 같은 특정차원에서 많은 연구들이 진행되었다 (S. Kim \& Kim, 2017). 아동학대와 방임이 아동의 정상적인 발 달과 성장을 저해하는 요소로서, 심리사회적 행동 문제나 신 체건강에 영향을 미친다는 연구들이 누적되어왔다. 심리사 회적으로는 불안과 우울, 사회적 위축(e.g., Park, 2014; Yoon, 1997), 공격성과 비행, 범죄(e.g., J. Y. Kim, Song, \& Han, 2010; S. Kim \& Lee, 2010; S. J. Kim \& Chung, 2013)등이 보고되었 고, 제한적이나 비만과 같은 신체적 건강(S. Y. Jung, 2012; Park $\& \mathrm{Kim}, 2018)$ 과도 관계가 있다는 점이 확인됐다. 그러나 지금 까지 한국의 연구들이 아동학대와 방임의 결과를 주로 발달적 측면에서 살펴봄으로써, 아동기의 노출이 장기적으로 성인기 의 건강과 관계하는지 생애과정관점(life-course perspective)에 서 연구되지 못한 한계가 있다. 또한, 대부분 학대와 방임을 경 험한 아동과 그렇지 않은 아동을 비교하거나 상관관계의 차원 에서 연구들이 진행됨(S. Kim \& Kim, 2017)에 따라, 한국에서 아동기에 겪게 되는 여러 부정적 경험들을 포함해서 $\mathrm{ACE}$ 의 중첩적인 노출과 패턴에 대한 이해가 부족한 게 사실이다. 
$\mathrm{ACE}$ 는 노출 시 한 가지 부정적 경험에 노출되기 보다는 여 러 부정적 경험에 노출되는 경향이 있다고 알려졌으며, 노출 되는 경험이 많아질수록 성인기 건강이 부정적이고 심각하게 나타난다는 점(dose-response manner)이 폭넓게 받아들여지고 있다(Dube et al., 2006; Hughes et al., 2017). 선행연구에서 이러 한 $\mathrm{ACE}$ 의 노출형태에 대한 조작적 정의는 크게 두 가지로 나 타나며, 하나는 ACE를 중첩적으로 측정(cumulative frequency scores)하는 형태와, 좀 더 최근에는 여러 부정적 경험 가운데 비슷한 ACE 패턴을 가진 그룹으로 유형화(discrete groups with similar patterns)하는 형태가 있다(Shin et al., 2018). 두 방식 모 두 같은 경험에 여러 번 노출된 것을 말하기 보다는, 서로 다 른 경험에 중첩적으로 노출된 것을 측정하는 방식이다. 먼저, $\mathrm{ACE}$ 를 중첩적으로 측정하는 접근은 $\mathrm{ACE}$ 연구 초기부터 진 행되어왔다. Kaiser 연구 결과에 따르면, 참여한 성인의 $2 / 3$ 가 적어도 한 개 혹은 그 이상의 $\mathrm{ACE}$ 를 경험하였고, 성인의 $1 / 5$ 가 3 개 또는 그 이상의 $\mathrm{ACE}$ 를 경험하여 대다수의 성인들이 한 가지 이상의 경험을 한 것으로 나타났다(Dube et al., 2006; Felitti et al., 1998). 이러한 누적적 경험은 흡연이나 약물중독 과 같은 신체적 질병을 유발하는 건강위험 행동에 영향을 미 치며, 특히 우울과 같은 심리 정서적 문제행동에 관계하는 것 으로 나타나, $\mathrm{ACE}$ 점수가 4점 또는 그 이상일 때 우울증상을 보일 가능성이 0점과 비교해 4.6배 증가하는 것으로 나타났다 (Chapman et al., 2004). 관련하여 한국에서 진행된 연구로는 S. $\operatorname{Kim}$ 과 $\operatorname{Kim}$ (2017)의 연구가 있으며, 대학생을 대상으로 11 가 지 경험을 $\mathrm{ACE}$ 아이템으로 측정하였다. 응답자의 약 $50 \%$ 가 한 가지 이상의 $\mathrm{ACE}$ 에 노출되었고, 약 $8 \%$ 가 4 개 혹은 그 이상 의 $\mathrm{ACE}$ 에 노출된 것으로 나타났다. 또한, $\mathrm{ACE}$ 의 누적점수가 증가할수록 우울과 알코올에 따른 문제행동이 나타날 가능성 이 커져, $\mathrm{ACE}$ 가 4점 또는 그 이상일 때 각각 5.6배, 4.6배 증가 하는 것으로 나타났다.

위의 연구들이 $\mathrm{ACE}$ 노출의 누적적 효과를 이해하는 데 도 움을 준 것이라면, $\mathrm{ACE}$ 를 유형화하는 연구는 잠재계층분석 (latent class analysis)을 통해서 아동기에 경험하는 ACE가 중 첩적으로 나타나는 경우에 어떤 구별되는 패턴이 존재하는 지 파악하고자 하는 것이다(Merians, Baker, Frazier, \& Lust, in press). 이는 ACE 노출패턴을 기반으로 개별적 대상자들을 분 류(person-centered approach)하는 방식으로, 대상자 각자가 경 험하는 ACE의 중첩적인 형태를 파악하고, 비슷한 패턴을 보 이는 대상자들을 묶어주는 것이다. 따라서 기존의 학대경험 유무에 따라 점수를 합산하거나, 어느 기준점을 중심으로 집 단을 연구자가 임의적으로 구분하는 것보다, $\mathrm{ACE}$ 노출에 비
슷한 패턴을 보이는 자연적으로 발생하는 집단을 경험적으로 확인할 수 있는 장점이 있다(S. Kim \& Lee, 2010; Merians et al., in press). 최근에 $\mathrm{LCA}$ 를 이용하여 $\mathrm{ACE}$ 를 유형화하는 연구들 이 나타나고 있으나, 각 연구마다 사용하는 샘플의 특성과 포 함시킨 부정적 경험들이 달라 유형화 결과가 일정하지는 않 다. 아동학대와 방임 및 가족기능 장애와 관련한 아동기 경험 을 적어도 한 개 이상씩 포함한 연구들을 살펴보면 다음과 같 다. 예를 들면, 미국의 성인을 대상으로 수집한 the National Epidemiologic Survey on Alcohol and Related Conditions (NESARC) 데이터를 이용한 Roos 등(2016)의 연구에서는 9개 의 부정적 경험을 5 가지로 유형화했을 때 데이터를 가장 잘 설 명하였고, ACE가 낮은 그룹, 신체와 정서학대 그룹, 부모 약 물중독과 방임 그룹, 부모의 높은 부적응 그룹, 그리고 다수의 $\mathrm{ACE}$ 에 노출된 그룹으로 구별되었다. 대규모 대학생을 대상 으로 한 연구에서는 9가지 부정적 경험을 4가지로 유형화했 을 때 데이터를 가장 잘 설명하였고, 낮은 $\mathrm{ACE}$ 그룹, 정서 및 신체적 학대그룹, 부모정신질환이나 약물중독 그룹, 그리고 $\mathrm{ACE}$ 가 전반적으로 높은 그룹으로 나타났으며(Merians et al., in press), 지역데이터를 이용한 연구에서는 13 가지 부정적 경 험이 4가지로 유형화되어, 낮은 $\mathrm{ACE}$ 그룹, 정서적 학대나 방 임 그룹, 가족원의 음주 또는 약물사용, 자살시도 가구원이 있 는 가족기능장애 그룹, 그리고 대체적으로 $\mathrm{ACE}$ 가 높은 그룹 으로 유형화되었다(Shin et al., 2018). 이러한 연구들의 결과는 대체적으로 $\mathrm{ACE}$ 가 낮은 그룹에 비해 높은 그룹이 성인기 음 주문제와 약물중독 그리고 우울과 같은 심리적 증상들에 유 의미하게 영향을 미쳤으며, 대학생의 경우에는 우울과 불안 에 강하게 영향을 미쳤다. 또한 가족기능장애보다는 부모로부 터의 학대경험이 이후의 건강문제를 더 잘 설명해주는 것으로 나타났다(Holt et al., 2017; Roos et al., 2016; Shin et al., 2018).

이처럼 해외에서 $\mathrm{ACE}$ 유형화 연구들이 진행되고 있는 것 과 달리, 한국에서 잠재계층분석을 이용해서 $\mathrm{ACE}$ 를 유형화한 연구는 본 연구자들이 아는 한 아직까지 없는 것으로 보인다. 다만, S. Kim과 Lee (2010)가 신체학대, 정서학대 그리고 방임 을 포함한 아동학대에 관한 잠재적 유형을 확인한 연구가 있 으나, 성인건강에 장기적으로 영향을 미칠 수 있는 아동기 여 러 부정적 경험들을 포함시키지 않았다. 따라서 본 연구는 잠 재계층분석을 이용해서 아동학대 및 가족기능 장애와 관련한 여러 아동기 부정적 경험들을 포함하여 유형화하고자 한다. 또한, 유형화가 성인기 우울, 정서조절의 어려움 및 대인관계 의 부적응과 같은 심리 정서적 문제에 영향을 미치는지 살펴 보고자 한다. 일반적으로 한국인의 정신건강 문제 중 발생률 
이 가장 높게 나타나는 것이 우울이며(J. W. Kim, Lee, Kang, \& Choi, 2013; S. Kim \& Kim, 2017), 앞서 제시한 해외 선행연구 에서 $\mathrm{ACE}$ 노출에 따른 심리 정서적 결과로 빈번히 지적된 것 이 우울이다(e.g., Almuneef et al., 2014; Chapman et al., 2004; S. Kim \& Kim, 2017; Shin et al., 2018). 뿐만 아니라, ACE 노출 은 우울 외에도 정서조절의 어려움 및 타인과의 친밀한 관계 를 형성하는데 부정적인 영향을 미칠 수 있다(J. W. Jung, 2014; Park, 2014; Pollack \& Sinha, 2002). 내부적으로 발생하는 부정 적인 감정에 적절히 대처할 만한 정서적지지 체계를 갖기 어 려운 양육환경으로 인해 정서조절의 어려움의 가능성이 크며 (Harter, 1998; J. Kim \& Cicchetti, 2006), ACE 노출에 따른 트 라우마로 인해 타인과의 관계에서 두려움과 위축되는 성향과 (Roberts, Kassel, \& Gotlib, 1995), 스스로에 대한 존중감이 낮고 타인과의 관계에 있어 작은 거부신호에도 민감해지는 등 대 인관계의 부적응이 나타날 수 있다(Gunnar \& Quewedo, 2007; M. J. Kim \& Yeum, 2012). 또한, 정서조절의 문제와 대인관계 의 스트레스가 우울에 영향을 미치는 중요 요인이며(Gotlib \& Hammen, 2009; J. W. Jung, 2014; Oh, Noh, \& Cho, 2009), 대인 관계에 대한 기술부족이 우울을 지속시키는 것으로 조사된 바 있다(Murray, Rose, Bellavia, Holmens, \& Kusche, 2002).

한편, $\mathrm{ACE}$ 외에 성인의 우울, 정서조절의 어려움 및 대인관 계 부적응에 영향을 미치는 변인으로 인구사회학적 요소들이 있다. 구체적으로 남성에 비해 여성이, 연령이 증가할수록, 월 평균 가구소득이 낮을수록 우울 수준이 높았으며(J. Kim, You, \& Song, 2015), 고졸 이상에 비해 고졸 이하의 학력을 가진 사 람들이 높은 우울 수준을 나타냈다(J. W. Jung, 2014). 또한, 남 성보다 여성이 정서조절의 어려움을 높게 인지하고 있었으며 (Hong \& Kim, 2017), 낮은 사회적 지위에 속한 사람일수록 정 서조절의 어려움으로 부정적인 정서를 경험할 가능성이 높았 다(Chen \& Miller, 2014; Gallo \& Matthews, 2003). 대인관계와 관련해서는 연령이 높아질수록 대인관계에 어려움을 덜 느끼 는 것으로 조사되었다(M. Y. Lee \& Nam, 2014).

이와 같이, 본 연구에서는 성별, 연령, 학력 및 소득과 같은 인구사회학적 특성을 포함하여 ACE 노출에 영향 받는 건강문 제로 우울, 정서조절의 어려움 및 대인관계 부적응 간의 관계 를 설명하고자 한다.

본 연구의 연구문제는 다음과 같다.

\section{연구문제 1}

아동기 부정적 생애경험(ACE)의 잠재적 유형은 어떠한가?

\section{연구문제 2}

아동기 부정적 생애경험(ACE)의 잠재적 유형은 우울, 정서적 조절의 어려움 및 대인관계 부적응에 영향을 미치는가?

\section{Methods}

\section{연구대상}

본 연구에서 사용한 자료는 성균관대학교 서베이리서치센터 에서 실시한 '2012년 한국종합사회조사(Korean General Social Survey [KGSS])'이다. KGSS는 미국 시카고대학교의 National Opinion Research Center에서 실시한 종합사회조사 (General Social Survey)를 기본 모형으로 설계된 한국판 전국표본조사사 업이다. 2003 년 제 1 차 설문을 시작으로 한국사회의 정치, 경제, 사회 등의 주요 요소들을 매년 조사하는 핵심설문과 해외국가 들과 공동으로 조사하는 연차적 주제모듈, 동아시아 국가들과 격년으로 조사하는 주제모듈, 특별연구를 위한 주제모듈 등으 로 해당연도의 요구와 필요에 따라 조사가 유기적으로 진행된 다(S. W. Kim, Kim, Moon, \& Shin, 2013). KGSS는 전국의 가구 거주 만 18 세 이상 성인 남녀를 모집단으로 여러 단계에 걸쳐 인구비례확률로 층화된 지역별 집락표본을 추출하는 방식인 다단계지역확률표집(multi-stage area probability sampling) 방식 으로 표본 추출하고, 면접원이 대상자를 직접 방문하여 일대일 면접을 통해 자료가 수집되었다(S. W. Kim et al., 2013).

본 연구는 KGSS가 해외국가들과 공동으로 조사하는 연차적 주제모듈로 2012년도에 수행된 '가족과 성역할의 변화 IV' 설 문을 통해 조사된 자료를 사용하였다. 2012년 설문조사는 18세 이전의 부정적 경험, 우울증상, 건강문제, 사회적 관계의 질, 정 서조절의 어려움 및 인구사회학적 배경을 질문하는 문항들이 포함되어 있다. 본 연구의 분석을 위해 2012년도에 만 18세에서 64 세 한국의 성인남녀 1,033 명의 응답 자료를 사용하였다.

\section{연구도구}

\section{종속변수}

우울 본 연구에서 우울은 KGSS의 2012년도 설문에서 사용된 Kroenke, Spitzer와 Williams (2001)에 의해 개발된 PHQ-9 (The Patient Health Questionnair-9) 척도를 사용하였다. PHQ-9은 자 가보고 형식으로 개발된 우울증을 평가하는 도구로 총 9문항 
으로 구성되어 있다. 각 문항들은 "잠들기 어렵거나, 너무 많이 잠", “피곤감, 기력저하", “식욕저하 또는 과식”, "일에 대한 흥 미나 재미가 거의 없음", "가라앉은 느낌, 우울감 또는 절망감", "내 자신이 나쁜 사람이거나 실패자라는 느낌", “신문이나 TV 에 집중하기 어려움", “거동이나 말이 너무 느리거나 반대로 안 절부절 못함”, “차라리 죽는 것이 낫겠다는 생각”이다. 각 문항 별로 응답한 지난 2주간의 우울 정도를 4점 리커트 척도(전혀 없었다[0], 일주일 미만 [1], 일주일 이상[2], 거의 매일[3])로 측 정되었다. 점수의 범위는 0 부터 27 점으로 해당 점수를 더한 측 정값이 높을수록 우울 수준이 높은 것을 의미한다. 척도의 신뢰 도를 확인한 결과 Cronbach's $\alpha$ 는 .84로 나타났다.

정서조절의 어려움 정서조절의 어려움은 Gratz와 Roemer (2004)가 개발한 정서조절곤란 척도(Difficulties in Emotion Regulation Scale) 중 2개의 문항을 사용하였다. 자가보고 형식 의 설문으로 "나는 감정에 압도되고 감정을 통제하기 힘들다 고 여긴다.”와 “화나거나 기분 나쁘면 내 행동에 대한 통제력 을 잃어버린다.”로 구성되었다. 각 문항은 5점 리커트 척도(전 혀 그렇지 않다[0] 매우 그렇다[4])로 측정되었으며, 점수의 범위는 0 부터 8 점으로 해당 점수를 더한 측정값이 높을수록 정서조절의 어려움을 겪고 있는 것을 의미한다. 척도의 신뢰 도를 확인한 결과 Cronbach's $\alpha$ 는 .75로 나타났다.

대인관계 부적응 대인관계 부적응은 Ryff (1989)가 개발한 심리적 안녕감 척도(Psychological Well-Being Scale) 중 대인관 계를 묻는 5 개의 문항으로 구성되었다. 각 문항을 살펴보면, "남들과 친밀한 인간관계를 유지하는 것이 어렵다.", "나의 고 민을 털어놓을 가까운 친구가 별로 없어 외로움을 느낀다.", "정말 필요할 때 내 말에 귀 기울여 줄 사람이 많지 않다.", "대 부분의 사람들이 나보다 친구를 더 많이 갖고 있는 것 같다.”, "다른 사람들과 신뢰 깊은 관계를 별로 경험하지 못했다."이 다. 각 문항들은 5점 리커트 척도(매우 그렇다[0] 전혀 그렇 지 않다[4])로 측정되었고, 모든 문항 점수를 역코딩 처리하였 다. 점수의 범위는 0 부터 20 점이였으며, 해당 점수를 더한 측 정값이 높을수록 대인관계 부적응이 높은 것을 의미한다. 척 도의 신뢰도를 확인한 결과 Cronbach's $\alpha$ 는 .80으로 나타났다.

\section{독립변수}

아동기 부정적 경험(Adverse Childhood Experiences [ACE]) 본 연구에서 ACE는 Bremner, Vermettem과 Mazure (2000)에 의
해 개발된 아동기 트라우마 척도(The Early Trauma Inventory Self-Report-Short Form [ETISR-SF]) 중 일반 트라우마 사건척 도와 아동학대를 묻는 문항들을 함께 사용하였다. 전통적으 로 ACE 연구는 아동기 경험을 8 가지로 범주화하여 측정하였 다. 학대와 관련하여 3 가지 신체, 정서, 그리고 성 학대를 포 함시키고, 가족기능 장애와 관련하여 5가지 가구원 중 교도 소 경험, 가정폭력(엄마가 매 맞는 경우), 음주 또는 약물 사용 자, 우울증 또는 정신병 또는 자살시도를 한 가구원, 부모가 이 혼하거나 한 부모 가정에서 아동기를 보낸 경우를 포함했다 (National Survey of Child and Adolescent Well-Being [NSCAW], 2018). 이후로 신체적 방임과 정서적 방임을 추가한 10 개의 아이템이 ACE 척도로 사용되어 왔다(CDC, 2018; NSCAW, 2018). 좀 더 최근에 Finkelhor, Shattuck, Turner와 Hamby (2013) 는 위에서 제시한 경험들 외에 그동안 아동발달과 관련한 종 단연구를 통해 밝혀진 건에 장기적으로 영향을 미칠 것으로 예측되어지는 경험을 $\mathrm{ACE}$ 아이템으로 제안하였다. 예를 들 면, 누군가 가까운 사람의 사고와 질병 경험, 평균 이하의 성적 그리고 또래폭력과 같은 경험이다.

본 연구에서는 KGSS가 사용한 ETISR-SF와 아동학대 문항 가운데 위에서 제시한 전통적인 10개 ACE 아이템과 Finkelhor 등(2013)이 제안한 아이템에 해당되는 문항들이 있으면 ACE 로 보았다. 이에 따라, ETISF-SF 척도에서 6범주(6개 문항)과 아동학대에서 4범주(11문항)를 사용하였다. 먼저, ETISF-SF 척도에서는 “부모 혹은 돌보아 주던 분의 사망 또는 질병” "부 모님의 이혼이나 별거", "형제/자매의 사망 또는 상해", "가족 원 중 폭력을 당하는 것을 목격(가정폭력)", "가족원의 정신질 환", “부모 혹은 돌보아 주던 분의 알코올이나 약물중독” 6개 문항을 사용하였다. 이 문항들은 경험여부를 물어본 것으로 경험이 있으면 1 , 경험이 없으면 0 값이 부여되었다. 다음으로 아동학대 11 문항들의 범주는 예, 아니오로 구성되었다. 먼저, 신체적 학대는 “손바닥으로 얼굴 맞음", "징벌로 뜨거운 물, 담 배 등에 화상”, “주먹으로 맞거나 발에 차임”, “징벌로 던진 물 건에 맞음", “징벌로 심하게 밀리거나 밀쳐짐" 5 문항 중 한 가 지라도 경험한 경우에 1 , 그렇지 않은 경우에 0 값을 부여하였 다. 정서적 학대는 "멸시나 비웃음", "무시를 당하거나 인정받 지 못함”, “쓸모없다는 말을 들음”에 대한 3 문항 중 한 가지라 도 경험한 경우에 1 , 그렇지 않은 경우에 0 값을 부여하였고, 방임은 “무관심하게 방치되거나 사랑받지 못함”, “부모님이 내가 필요로 하는 바를 이해 못함” 2 문항 중 한 가지라도 경험 한 경우에 1 , 그렇지 않은 경우 0 값을 부여하였다. 마지막으로 성적학대는 “성적으로 불쾌한 육체적 접촉경험" 을 한 경우 1 , 
그렇지 않은 경우 0 값을 부여하여 총 10 개의 경험을 $\mathrm{ACE}$ 으로 구성하였다.

\section{통제변수}

통제변수는 아동기 부정적 경험 외에 우울, 정서조절 어려움, 대인관계 부적응에 영향을 미칠 수 있는 인구사회학적 배경 변수로 성별, 연령, 월평균 가구소득 그리고 학력수준을 분석 에 포함하였다. 성별은 남성은 1 , 여성은 0 으로 구분하였고, 연령은 연구대상자들이 응답한 나이로 연속변수로 측정하였 다. 학력수준은 고등학교 졸업 여부로 측정하였으며, 월평균 가구 총소득은 응답한 월 가구소득에 대해 로그 $(\log )$ 로 변환한 값을 사용하였다.

\section{자료분석}

본 연구에서는 $\mathrm{ACE}$ 에 따라 잠재계층을 분류하고 분류된 잠재 계층이 성인의 우울, 정서조절의 어려움과 대인관계 부적응에 영향을 미치는지를 살펴보기 위해 다음과 같이 자료를 분석하 였다. 먼저, 독립변수인 아동기 부정적 경험은 응답자의 18 세 이전 경험을 의미하며, 우울을 포함한 종속변수와 성별 등의 통제변수는 응답자의 현재시점을 의미한다. 예를 들어, 응답 자가 청년기(만 18-30세)에 해당할 경우, 아동기 부정적 경험 은 그들의 18 세 이전의 경험을 의미하며, 우울과 같은 종속변
수와 성별 등의 통제변수는 만 18 에서 30 세에 해당하는 각 대 상자들의 응답시점 점수를 사용하였다. 마찬가지로 응답자가 중년기(만 50-64세)에 해당할 경우에도, 아동기 부정적 경험 은 그들의 18 세 이전 경험을 의미하며, 종속변수와 통제변수 는 만 50-64세에 해당하는 응답시점의 점수를 사용하였다.

분석은, 아동기 부정적 경험에 대해 조사된 10 개 경험을 간 명하게 분류하기 위해 혼합모형의 일종인 잠재계층분석(latent class analysis)을 수행하였다. 혼합모형은 평균적인 변수간의 관계 설명에 초점을 두기보다는 알려지지 않은 몇 개의 이질 적인 하위집단으로 분류하는 데 유용한 방법으로(S. Kim \& Kim, 2017; McLachlan \& Peel, 2000), 전체 모집단에서 ACE에 따라 알려지지 않은 하위집단(잠재계층)이 여러 개의 구분되 는 집단들로 섞여 있다는 것을 파악하기에 유용한 통계적 방 법이다. 하위집단이 몇 개의 그룹일 때 데이터를 가장 잘 설명 하는 적합한 모형인지 선택하기 위해 잠재계층의 수를 늘려가 면서 $\mathrm{k}$ 개 잠재계층모형과 $\mathrm{k}-1$ 개 잠재계층모형을 비교하면서 선택하였다. 비교 시 많이 사용하는 기준은 Akaike Information Criterion (AIC), Bayesian Information Criterion (BIC), LoMendell-Rubin Adjusted Likelihood Ration Test (LMRT)값, Entropy값 등이다. 정보기준지수인 $\mathrm{AIC}$ 와 $\mathrm{BIC}$ 는 모형 중 적 은 값을 갖는 모형을 선호하며, 분류된 잠재계층의 질을 알려 주는 정보인 Entropy값은 1 에 가까울수록 잠재계층 분류의 정 확성을 알려준다. 또한, 교정 $\chi^{2}$ 분포에 기반 한 LMRT 검증 결 과가 유의미한 경우 잠재계층 수를 늘렸을 때 모형개선이 이

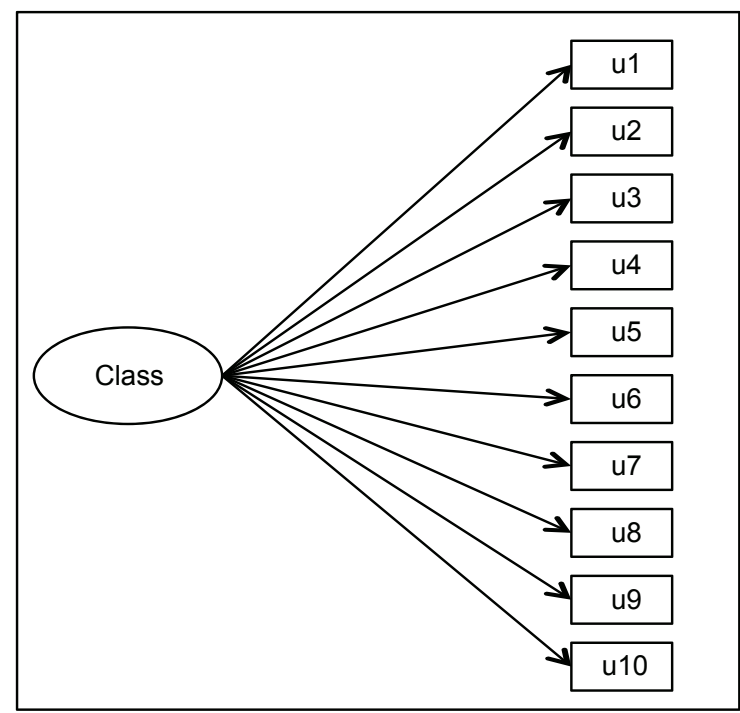

Level 1: Latent Class Analysis

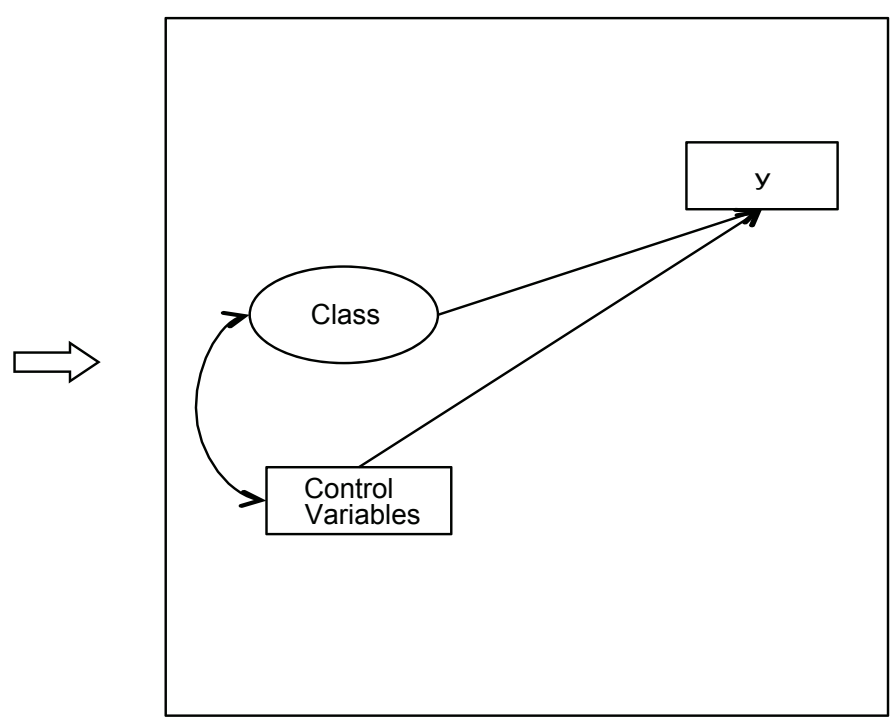

Level 2: Including Outcome Variables

Figure 1. Process of latent class analysis. 
루어졌음을 의미하고, 유의미하지 않을 경우 모형개선이 이 루어지지 않은 것을 의미하므로, 적합한 모형으로 k-1개 잠재 계층 모형을 선택한다(Lo, Mendell, \& Rubin, 2001; Lubke \& Muthen, 2007; Nylund, Asparouhov, \& Muthen, 2007). 다음으 로 잠재계층분석을 통해 선택된 유형화 그룹이 성인의 우울, 정서조절의 어려움과 대인관계 부적응에 영향을 미치는지 살 펴보기 위해 회귀분석을 실시하였다(Figure 1). 분석은 통계프 로그램 Mplus version 4.21 (Muthén \& Muthén, 2007)을 사용하 였다.

\section{Results}

\section{응답자 일반적 특성}

연구대상자들의 인구사회학적 특성을 살펴보면, 남성이 $45.2 \%$, 여성이 $54.8 \%$ 였다. 평균 연령은 42.4 세 $(S D=13.2)$ 였 으며, 연령범주는 만 18 세에서 64 세까지로 만 18 세에서 만 30 세까지가 $22.8 \%$, 만 31 세에서 만 50세 미만이 약 $45.6 \%$, 그리 고 만 51 세 이상이 $31.6 \%$ 를 차지하였다. 연구대상자의 교육 수준은 $1.5 \%$ 가 정규교육을 받지 못했으며, 초졸 혹은 중졸이 $17.5 \%$, 고졸 $34.5 \%$, 전문대 졸업 또는 그 이상이 $46.5 \%$ 였다. 평균 가구 총소득은 약 420 만원이었다(Table 1). 또한, 연구대 상자들의 우울의 평균은 $4.42(S D=4.49$, range $0-27)$, 정서조
절의 어려움 평균은 $2.32(S D=1.85$, range $0-8)$ 이였으며, 대인 관계 부적응의 경우, 평균은 $7.54(S D=3.90$, range $0-20)$ 로 나 타났다(Table 1). 본 연구대상자들의 전반적인 정신건강의 특 성을 우울의 수준에서 봤을 때, PHQ-9 척도의 경우, 0-4점은 우울증이 아님, 5-9점은 가벼운 우울증, 10-19점은 중간 정도 우울증, 20-27점은 심한 우울증으로 평가(Hwang \& Oh, 2014) 됨에 따라, 본 연구에서는 평균적으로 우울증을 동반하지 않 은 연구대상자들의 자료를 사용하였다고 볼 수 있다.

\section{$\mathrm{ACE}$ 잠재계층 유형}

$\mathrm{ACE}$ 에 대한 유형 확인을 위해 잠재계층분석을 실시하였으며, 몇 개의 하위집단으로 구분되는지 확인하기 위해 집단의 수를 하나씩 늘려가며 AIC와 BIC, Entropy값, 그리고 LMRT값 등 을 확인하였다. Table 2에서와 같이 AIC값은 지속적으로 감소 하였으나, BIC 값은 3집단 모형까지 감소하다가 4집단 모형에 서 증가하였다. LMRT 결과는 2집단에서 4집단까지 .05수준 이상에서 유의한 반면, 5 집단 모형은 유의하지 않아 4집단에 서 5집단으로 늘렸을 때 모형개선이 이루어지지 않음을 보여 주었다. Entropy값은 일반적으로 .70 이상의 값을 가질 경우 비 교적 정확히 분류되는 것으로 볼 수 있으며(Nagin, 2005), 4집 단 모형은 .68로 .70에 미치지 못했다. 따라서 위의 통계적 비 교기준들을 고려할 때, 3 집단 모형이 자료를 최적으로 설명하 고 있는 것으로 보았다.

Table 1

Descriptive Statistics of the Study Sample

\begin{tabular}{|c|c|c|c|}
\hline \multicolumn{2}{|c|}{ Variables } & \multirow{2}{*}{$\begin{array}{c}\text { Frequency }(\%) \text { or Mean } \\
467(45.2 \%)\end{array}$} & \multirow[t]{2}{*}{$(S D)$} \\
\hline Gender & Male & & \\
\hline & Female & $566(54.8 \%)$ & \\
\hline \multirow[t]{3}{*}{ Age } & $18-30$ & $236(22.8 \%)$ & \\
\hline & $31-50$ & $471(45.6 \%)$ & \\
\hline & $51-64$ & $326(31.6 \%)$ & \\
\hline \multirow[t]{5}{*}{ Educational level } & No education & $15(1.5 \%)$ & \\
\hline & Elementary school & $83(8.0 \%)$ & \\
\hline & Middle school & $98(9.5 \%)$ & \\
\hline & High school & $356(34.5 \%)$ & \\
\hline & College or higher & $481(46.5 \%)$ & \\
\hline \multicolumn{2}{|c|}{ Monthly average household income (KRW 10,000) } & 419.88 & $(523.09)$ \\
\hline \multicolumn{2}{|c|}{ Depressive symptoms (range $0-27$ ) } & 4.42 & $(4.49)$ \\
\hline \multicolumn{2}{|c|}{ Difficulty in emotion regulation (range $0-8$ ) } & 2.32 & $(1.85)$ \\
\hline \multicolumn{2}{|c|}{ Interpersonal maladjustment (range $0-20)$} & 7.54 & $(3.90)$ \\
\hline
\end{tabular}

Note. $N=1,033 . S D=$ standard deviation. 
Table 2

Model Fit Indices of Latent Class Analysis for Classes 1-5

\begin{tabular}{|c|c|c|c|c|}
\hline Number of classes & AIC & $\mathrm{BIC}$ & Entropy & LMRT \\
\hline 1 & 8701.13 & 8750.53 & - & - \\
\hline 2 & 7775.99 & 7879.74 & .78 & $934.89^{* * *}$ \\
\hline 4 & 7687.84 & 7900.30 & .68 & $52.17^{*}$ \\
\hline 5 & 7684.36 & 7951.13 & .75 & 25.18 \\
\hline
\end{tabular}

${ }^{*} p<.05 .{ }^{* * *} p<.001$.

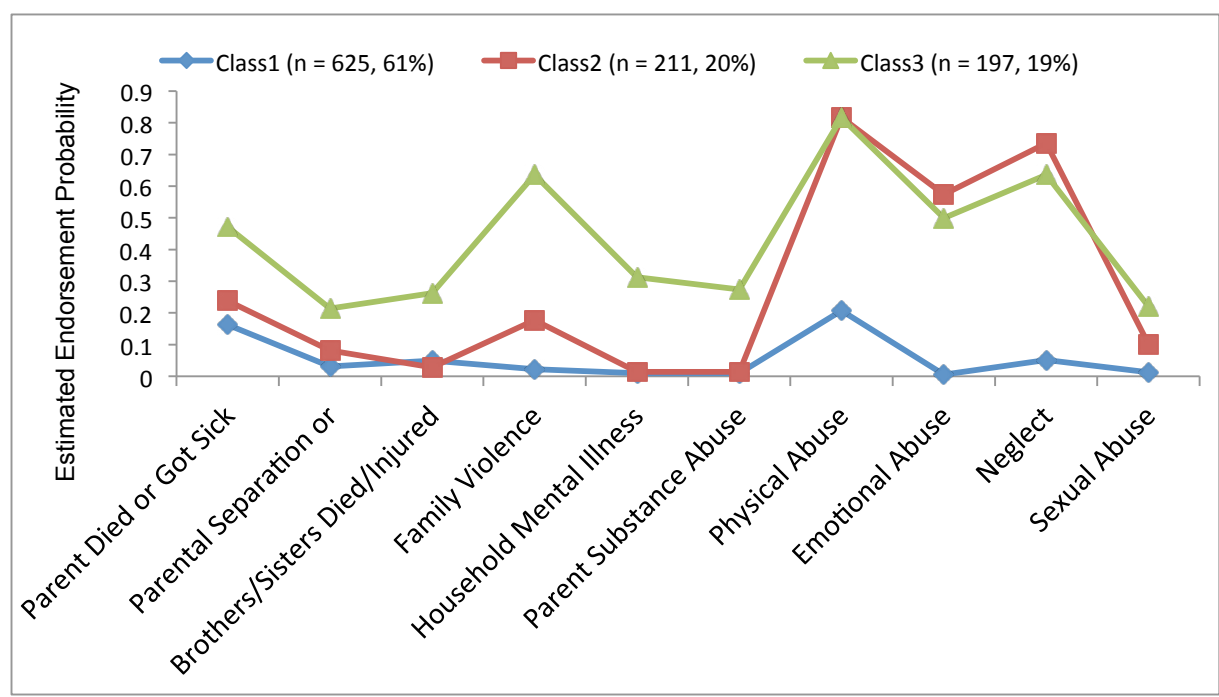

Figure 2. Item-response probabilities for $10 \mathrm{ACE}$ across three classes (ages 18-64 years). Class $1=$ low ACE group; Class $2=$ child maltreatment group; Class 3 = family violence and child maltreatment group.

다음의 Figure 2는 만 18세부터 64세까지 연구대상자들에 대한 최적모형으로 선정된 3집단 모형을 그래프로 나타낸 것 이다. 첫 번째 집단(class 1)은 10 가지 ACE가 대체적으로 낮은 분포를 이루고 있어 '낮은 ACE' 그룹이라 명명하였다. 두 번째 집단은 $\mathrm{ACE}$ 가운데 대부분 낮은 분포를 이루고 있으나, '신체 적 학대’, ‘정서적 학대 및 방임’ 경험이 특히 높게 나타나는 집 단으로 '아동학대 집단'이라 명명하였다. 마지막으로 세 번째 집단은 두 번째 집단과 같이 신체적 학대, 정서적 학대 및 방임 경험이 높게 나타남과 동시에 '가정폭력' 또한 높게 나타난 경 우로 '가정폭력 및 아동학대 집단'이라 명명하였다. 이러한 3 집단 모형의 각 집단 크기는 $60.5 \%(n=625$ 명, 1 유형 $), 20.4 \%(n$ = 211명, 2 유형 $)$, 그리고 $19.1 \%(n=197$ 명, 3 유형 $)$ 로 나타났다.

참고로, 본 연구가 사용한 자료의 대상자 연령 분포가 넓 어, 청년기(만 18-30세), 장년기(만 31-49세) 그리고 중년기(만 50-64세) ACE 유형을 확인해 보았다. 잠재계층분석 결과, 청 년기, 장년기, 중년기에서 모두 3 집단 모형이 자료를 최적으
로 설명하고 있었으며, 그 유형화의 패턴도 $\mathrm{ACE}$ 노출이 낮은 $\mathrm{ACE}$ 집단, 아동학대 집단, 가정폭력 및 아동학대 집단으로 모 두 매우 유사하게 나타났다.

Table 3은 10 개 ACE 아이템의 분포를 보여주고 있다. 연구 대상자 전체의 약 $46 \%$ 가 신체적 학대를 경험한 것으로 나타 나 가장 높은 분포율을 보였다. 다음으로 방임 약 $32 \%$, 부모사 망 또는 질병이 약 $24 \%$, 정서학대 약 $23 \%$, 가정폭력 약 $18 \%$ 등의 순으로 나타났다. 유형화에 따른 분포도를 보면, 낮은 $\mathrm{ACE}$ 집단의 아동기 부정적 경험 분포가 전반적으로 낮았으나, 이 하위집단의 약 $21 \%$ 가 신체학대를 경험하였고, $17 \%$ 가 부 모 사망 또는 질병을 경험한 것으로 나타났다. 또한, 아동학대 집단의 경우는 학대관련 경험이 특히 높게 나타나, 약 $85 \%$ 가 신체학대, 약 $81 \%$ 가 방임, 약 $65 \%$ 가 정서적 학대를 경험하였 다. 또한, 해당집단의 약 $21 \%$ 가 부모 사망 또는 질병, 약 $16 \%$ 가 가정폭력을 경험한 것으로 나타났다. 마지막으로 가정폭력 및 아동학대집단의 경우는 ACE 전반에 걸쳐 다른 두 집단에 
Table 3

Descriptive Statistics of ACE Prevalence Rates

\begin{tabular}{|c|c|c|c|c|}
\hline \multirow[b]{2}{*}{ ACE } & \multirow[b]{2}{*}{$\begin{array}{c}\text { Entire Sample } \\
\qquad \begin{array}{c}N=1,033 \\
(\%)\end{array}\end{array}$} & \multicolumn{3}{|c|}{ ACE patterns } \\
\hline & & $\begin{array}{c}\text { Low ACE } \\
\begin{array}{c}n=625 \\
(\%)\end{array}\end{array}$ & $\begin{array}{l}\text { Child maltreatment } \\
\qquad \begin{array}{c}n=211 \\
(\%)\end{array}\end{array}$ & $\begin{array}{l}\text { Family violence and } \\
\text { child maltreatment } \\
\qquad \begin{array}{c}n=197 \\
(\%)\end{array}\end{array}$ \\
\hline Parent died or got sick & 24.1 & 17.0 & 20.9 & 50.3 \\
\hline Parental separation or divorce & 7.8 & 3.4 & 7.6 & 22.3 \\
\hline Brothers/sisters died or injured & 8.8 & 5.1 & .9 & 28.9 \\
\hline Family violence & 17.9 & 1.8 & 15.6 & 71.6 \\
\hline Household mental illness & 7.2 & 1.0 & .0 & 34.5 \\
\hline Parent substance abuse & 6.4 & .8 & .0 & 31.0 \\
\hline Physical abuse & 46.0 & 21.4 & 84.8 & 82.2 \\
\hline Emotional abuse & 22.7 & .0 & 64.9 & 49.2 \\
\hline Neglect & 31.6 & 5.3 & 80.6 & 62.4 \\
\hline Sexual abuse & 7.4 & 1.0 & 10.4 & 24.4 \\
\hline
\end{tabular}

Table 4

Regression Analyses Indicating the Relationship Between ACE Classes and Outcome Variables

Depressive symptoms Difficulty of emotion regulation Interpersonal maladjustment

\begin{tabular}{llll} 
& \multicolumn{1}{c}{$\beta(S E)$} & $\beta(S E)$ & $\beta(S E)$ \\
Age (range 18-64) & $-.01(.003)^{* * *}$ & $-.01(.003)^{* *}$ & $-.001(.003)$ \\
Gender (male = 1) & $-.20(.06)^{* * *}$ & $-.08(.06)$ & $-.16(.06)^{* *}$ \\
Monthly average household income (KRW 10,000) & $-.08(.03)^{* *}$ & $-.03(.03)$ & $-.10(.03)^{* * *}$ \\
Educational level (high school = 1) & $-.39(.09)^{* * *}$ & $-.11(.09)$ & $-.27(.09)^{* *}$ \\
ACE classes & & $.24(.08)^{* * *}$ & $.30(.08)^{* * *}$ \\
$\quad$ Child maltreatment group & $.42(.07)^{* * *}$ & $.34(.08)^{* * *}$ & $.43(.08)^{* * *}$ \\
$\quad$ Family violence and child maltreatment group & $.75(.07)^{* * *}$ &
\end{tabular}

Note. $N=1,033$. All regression analyses were controlled for age, gender, educational level and monthly average of household income. Low ACE Group was used as the reference group.

${ }^{* *} p<.01 .{ }^{* * *} p<.001$.

비해 높은 분포를 보인 가운데, 약 $82 \%$ 가 신체학대, 약 $72 \%$ 가 가정폭력, 약 $62 \%$ 가 방임 그리고 약 $49 \%$ 가 정서적 학대를 경 험한 경우가 특히 높았다. 이 유형에 해당하는 집단은, 부모 사 망 또는 질병이 $50 \%$ 로 나타났으며, 이외에도 이 집단의 10 명 중에 약 3 명은 가족의 정신질환이나 부모 알코올 및 약물사용 가정에서 성장한 것으로 나타났다.

\section{$\mathrm{ACE}$ 유형이 우울, 정서조절의 어려움 및 대인 관계 부적응에 미치는 영향}

$\mathrm{ACE}$ 의 유형이 이후의 우울이나 정서조절의 어려움 그리고 대 인관계 부적응에 미치는 영향을 살펴보기 위해서 회귀분석 $(N$
$=1,033)$ 을 실시하였다. 먼저, 낮은 $\mathrm{ACE}$ 집단을 기준집단으로 했을 때, 회귀분석의 결과는 Table 4 와 같다. 인구사회학적 요 소를 통제하고, 아동학대 집단이 낮은 $\mathrm{ACE}$ 집단에 비해 우울 감이 높았으며 $(\beta=.42, p<.001)$, 정서조절의 어려움을 더 높 게 인식하고 있었고 $(\beta=.24, p<.001)$, 대인관계 부적응이 높 았다 $(\beta=.30, p<.001)$. 마찬가지로, 인구사회학적 요소를 통 제하고, 가정폭력 및 아동학대집단이 낮은 ACE집단에 비해 우울정도 높게 나타났으며 $(\beta=.75, p<.001)$, 정서조절의 어려 움을 더 높게 인식하고 있으며 $(\beta=.34, p<.001)$, 대인관계 부 적응이 높았다 $(\beta=.43, p<.001)$.

이러한 회귀분석을 청년기, 장년기, 중년기에 적용했을 때 에도 유사한 결과가 타났다. 청년기, 장년기, 중년기에 걸쳐 낮 
은 ACE 집단에 비해 아동학대 집단 및 가정폭력 및 아동학대 집단이 우울정도가 높았으며, 정서조절의 어려움을 더 높게 인식함과 동시에 대인관계 부적응이 높았다. 다만, 청년기(만 18세 30세)를 대상으로 한 다중회귀분석에서는 낮은 ACE 집단과 아동학대 집단 간의 대인관계 부적응과는 관계가 없었 다 $(\beta=.04, p=60$.$) .$

또한, 아동학대 집단과 가정폭력 및 아동학대집단 각각을 기준집단으로 해서 회귀분석의 패턴을 확인해보았다. 그 결 과, 가정폭력 및 아동학대집단이 아동학대 집단보다 우울정도 가 유의미하게 높았으나, 정서조절의 어려움이나, 대인관계 부적응과는 유의미하지 않게 나타났다. 아동학대 집단을 비교 집단으로 두었을 때도, 회귀분석의 결과는 위와 같은 패턴을 보였다. 따라서 아동학대 집단과 가정폭력 및 아동학대집단이 낮은 $\mathrm{ACE}$ 집단에 비해 전반적으로 심리 정서적 어려움을 높 게 인식하였고, 아동학대 집단에 비해서는 가정폭력 및 아동 학대집단이 우울을 높게 인식했다.

\section{Discussion}

본 연구는 아동학대와 가족기능 장애를 포함한 $\mathrm{ACE}$ 를 유형화 하고, 유형화가 성인기 우울, 정서조절 및 대인관계 문제에 영 향을 미치는지 살펴보았다. 이를 위해, 2012년 한국종합사회 조사에서 수집된 전국 만 18 세 이상 성인남녀 1,033 명의 자료 를 활용하여 잠재계층모형과 다중회귀분석을 실시하였다. 10 개의 아동기 부정적 경험을 $\mathrm{ACE}$ 로 구성하고, 잠재계층모형을 이용해서 하위집단이 몇 개의 그룹일 때 데이터를 가장 잘 설 명하는 적합한 모형인지를 비교 선택하면서, $\mathrm{ACE}$ 에 대한 하 위집단을 파악하였다.

분석결과, 만 18세에서 64세까지 일반 성인을 대상으로 한 $\mathrm{ACE}$ 의 유형은 3 개의 하위집단으로 유형화되었다. 전체 연구 대상의 약 $60 \%$ 가 낮은 ACE 집단에 속했으나, 나머지 약 $40 \%$ 가 아동학대 집단 혹은 가정폭력 및 아동학대 집단으로 $\mathrm{ACE}$ 에 노출된 위험집단에 속했다. 특히, 전체 연구대상의 $19 \%$ 에 해당하는 가정폭력 및 아동학대 집단은 아동학대 및 가정폭력 노출이 두드러지게 높았으며, 가구기능 장애로 나타나는 가 구원의 정신질환 및 부모의 약물사용에서도 상당수의 대상자 들이 노출되어 고 위험집단으로 나타났다. 비록 ACE 유형분 류에서 18 세 이전에 부모가 죽거나 질병을 경험한 경우가 높 은 분포를 차지하나, 결과 해석에 있어 크게 고려하지 않았는 데, 연령이 높은 집단이 포함될수록 아동기에 부모의 사망 혹
은 심각한 질병에 노출되는 경우가 많아져, 연령효과가 나타 난 것으로 보았고, 이러한 효과는 형제 혹은 자매의 사망 혹은 상해의 경우도 마찬가지였다.

지금까지 한국에서 ACE 유형화 결과와 비교할 만한 연구 가 없어 해외연구와 비교해보면 다음과 같은 패턴을 확인할 수 있다. 선행연구에서 포함시킨 ACE가 일치하지 않아 직접 적인 비교는 어려우나 그 패턴 속에서 유사점과 차이점을 찾 아볼 수 있다. 잠재계층모형을 사용해서 분석한 선행 연구들 의 결과에 따른 하나의 패턴은 $\mathrm{ACE}$ 가 높은 집단과 $\mathrm{ACE}$ 가 낮 은 집단으로 분류되는 경향(e.g., Cavanaugh, Petras, \& Martins, 2015; Merians et al., in press; Roos et al., 2016)이 있으며, 연구대 상의 소수가 ACE가 높은 집단에 속하나 다수의 부정적 경험 에서 높은 분포를 보이는 집단이다. 이러한 경향은 본 연구 결 과에도 해당하는 부분으로 가정폭력 및 아동학대 집단이 속한 다고 볼 수 있다. 또한, 본 연구를 통해서 보면, 아동학대만 높 게 나타난 집단은 있었으나, 가정폭력만 높게 나타나는 집단 은 없었다. 이러한 점은 한국에서 아동학대 예방적 차원에서 가정폭력이 동반되는지 반드시 확인이 요구되며, 가정폭력이 동반될 때 다수의 부정적 경험을 함께 할 가능성이 높다는 것 을 고려할 필요가 있다.

또 하나의 패턴은 신체적 학대와 정서적 학대를 포함한 아 동학대 집단과 가구원의 정신질환이나 부모의 약물사용과 같 은 가족기능 장애집단으로 유형화되는 점이다(e.g., Menard,

Bandeen, Roche, \& Chilcoat, 2004; Merians et al., in press; Shin et al., 2018). 본 연구 결과에서는 '아동학대 집단'이 잠재적 하위 집단으로 유형화되었으나, 가구원의 정신질환이나 부모의 약 물사용에 대한 분포가 전반적으로 낮아 가족기능 장애집단이 유형화되어 나타나지 않은 해외연구와의 차이가 있다. 이러한 점에 비춰볼 때, 앞으로 한국에서 가정 내 폭력과 관련한 요인 을 좀 더 세분화하여 살펴보는 등 한국인의 성인기 건강에 영 향을 미칠 것으로 예상되는 아동기 부정적 경험과 관련한 많 은 연구들이 요구되어진다.

또한, 본 연구는 $\mathrm{ACE}$ 유형화에 따라 성인기 우울, 정서조절 및 대인관계 문제에 영향을 미치는지 살펴보았다. 그 결과, 아 동학대 집단과 가정폭력 및 아동학대 집단 모두 낮은 ACE 집 단에 비해 성인기 심리 정서적 문제에 부정적 영향을 미쳤으 며, 다수의 부정적 경험에 노출된 가정폭력 및 아동학대 집단 이 아동학대 집단에 비해 성인기 우울을 높게 인식하고 있었 다. 이러한 결과는 선행연구와도 일반적으로 일치하는 것으 로, 아동학대가 성인기 심리 정서적 문제, 특히 우울에 영향을 미치며(e.g., Chapman et al., 2004; S. Kim \& Kim, 2017; Merrick 
et al., 2017), 다수의 부정적 경험에 노출된 경우에 그렇지 않 은 집단에 비해 성인기 우울을 포함한 심리 정서적 문제를 경 험할 가능성이 더 높게 나타난 것(e.g., Chapman et al., 2004; Edwards, Holden, Felitti, \& Anda, 2003; Ford et al., 2016)과 같다. Hughes 등(2017)의 메타분석에서도 이러한 결과를 지지하고 있는데, 중국, 베트남을 포함한 해외 여러 나라들의 37개 연구 결과를 종합한 결과 아동학대 집단 및 다수의 $\mathrm{ACE}$ 노출집단 들이 우울을 포함한 정신건강과 강한 상관관계가 있었다.

이와 같이, $\mathrm{ACE}$ 노출이 생애 장기간 영향을 미친다는 연 구들이 보고되고 있으나 해외에서도 $\mathrm{ACE}$ 에 대한 예방을 위 한 정책적, 실천적 논의가 느리게 진행되고 있다는 점이 지적 되고 있다(Hughes et al., 2017). 현재, 건강과 관련한 세팅에서 전문가들에 대한 $\mathrm{ACE}$ 교육 및 사정 단계에서 $\mathrm{ACE}$ 히스토리 에 대한 정보 수집을 통해 좀 더 적합한 개입이 선택될 수 있도 록 ACE 인폼드 실천(ACE-informed practice)이 제안되고 있으 며(Glowa, Olson, \& Johnson, 2016; Hughes et al., 2017). 이러한 실천은 건강세팅 외에도 학교나 사회적 돌봄 세팅 그리고 교 정 기관에서도 활용될 수 있을 것이다(Hughes et al., 2017). 미 국의 American Association of Pediatrics는 아동과 가족을 대상으 로 하는 의료세팅에서 외상 인폼드 케어(trauma-informed care) 를 통해 전문가들의 $\mathrm{ACE}$ 교육 및 개입적 노력이 진행되고 있 다(The Child Health Data, 2016). 이것의 가장 큰 목표는 외상 을 겪은 이들의 회복과 임파워먼트로, 서비스 제공자들이 환 자와 그 가족에 대한 무의식적인 편견을 갖지 않도록 트레이 닝하고, 환자와 그 가족에게 외상에 대해 교육하고 $\mathrm{ACE}$ 에 따 른 신체적 그리고 정신적 외상후 증세를 인지해서 안전한 회 복을 이룰 수 있도록 돕는 등의 내용이 포함되어 있다. 한국의 경우에도 본 연구를 통해 나타난 바와 같이, 일반 성인 중 일부 는 다수의 $\mathrm{ACE}$ 에 노출된 고 위험군에 속할 수 있어, 적어도 정 신건강 세팅에서 서비스 제공자에 대한 $\mathrm{ACE}$ 교육 및 대상자 가 외상을 인지하고 회복해 나갈 수 있는 개입적 접근이 적극 모색될 필요가 있다. 그럼에도 불구하고, 아직까지 한국에서 는 ACE가 어떠한 유형으로 존재하고 어느 정도 확산되어 있 는지, $\mathrm{ACE}$ 에 따른 전 생애에 걸친 건강문제 등에 대한 축적된 지식이 미비한 상태이다. 먼저, $\mathrm{ACE}$ 연구의 활성화를 통해 아 동학대와 가정폭력의 역할을 폭넓은 시각에서 바라보고, 예방 과 개입을 위한 좀 더 면밀한 조사가 요구되는 단계이다.

이러한 연구결과와 함의에도 불구하고 본 연구는 다음과 같은 한계점을 갖는다. 첫째, 본 연구에서 사용한 한국종합사 회조사가 횡단조사를 통해 자료를 수집함으로써, $\mathrm{ACE}$ 와 성인 기 우울이 시간적 순서에 따라 수집되지 못한 한계가 있다. 후
향적 자료수집 방법으로 인해 아동기 $\mathrm{ACE}$ 경험에 대한 과소 혹은 과대 보고되었을 가능성을 배제할 수 없다. 그러나 본 연 구에서 생애주기적으로 $\mathrm{ACE}$ 유형화가 같은 패턴으로 나타난 점을 미뤼볼 때는 유형화 연구에 있어 후향적 자료수집이 크 게 영향을 미치지 않을 수 있으며. 따라서 앞으로 이러한 점은 더 많은 종단연구를 포함한 후속 연구들이 이뤄질 필요가 있 겠다. 둘째, 본 연구에서 사용한 종속변수는 우울과, 정서적 조 절의 어려움 및 대인관계 부적응에 대한 자기보고식 데이터를 사용함에 따라 $\mathrm{ACE}$ 와 증상에 대한 좀 더 안정적인 확인을 위 해 표준화된 프로그램을 사용하여 심층적인 조사가 요구된다. 종합적으로, 본 연구는 $\mathrm{ACE}$ 를 측정하고 유형화가 나타나는지 를 살펴 본 후 유형화에 따른 성인기 건강에 차이가 있는지에 관한 연구자가 아는 한 한국에서 처음 시도된 연구로, 기존 연 구들이 주로 아동학대와 방임에 국한되어 그 영향력을 살펴본 것에서 탈피해 아동기에 예상되는 다양한 부정적 경험들을 포 괄해 그 영향력을 살펴보았다. 이에 따라, 기존의 지식을 확장 하는 데 학문적 그리고 실천적 의의가 있으며, 앞으로 ACE 연 구의 활성화에 기여하고자 한다.

\section{Acknowledgements}

This study was supported by the Ministry of Education of the Republic of Korea and the National Research Foundation of Korea (NRF-2016S1A3A2924375).

\section{Conflict of Interest}

No potential conflict of interest relevant to this article was reported.

\section{References}

\section{In English}

Almuneef, M., Qayad, M., Aleissa, M., \& Albuhairan, F. (2014). Adverse childhood experiences, chronic diseases, and risky health behaviors in Saudi Arabian adults: A pilot study. Child Abuse \& Neglect, 38(11), 1787-1793. doi:10.1016/ j.chiabu.2014.06.003

Anda, R. F., Felitti, V. J., Bremner, J. D., Walker, J. D., Whitfield, 
C., Perry, B. D., . . Giles, W. H. (2006). The enduring effects of abuse and related adverse experiences in childhood: A convergence of evidence from neurobiology and epidemiology. European Archives of Psychiatry and Clinical Neuroscience, 256(3), 174-186. doi:10.1111/ j.1365-2214.2006.00614_2.x

Anda, R. F., Whitfield, C. L., Felitti, V. J., Chapman, D., Edwards, V. J., Dube, S. R., \& Williamson, D. F. (2002). Adverse childhood experiences, alcoholic parents, and later risk of alcoholism and depression. Psychiatric Services, 53(8), 10011009. doi:10.1176/appi.ps.53.8.1001

Bellis, M. A., Hughes, K., Leckenby, N., Hardcastle, K. A., Perkins, C., \& Lowey, H. (2015). Measuring mortality and the burden of adult disease associated with adverse childhood experiences in England: A national survey. Journal of Public Health, 37(3), 445-454. doi:10.1093/pubmed/fdu065

Bellis, M. A., Hughes, K., Leckenby, N., Jones, L., Baban, A., Kachaeva, M., . . . Terzic, N. (2014). Adverse childhood experiences and associations with health-harming behaviours in young adults: Survey in eight eastern European countries. Bulletin of the World Health Organization, 92(9), 641-655B. doi:10.2471/blt.13.129247

Braveman, P., \& Barclay, C. (2009). Health disparities beginning in childhood: A life-course perspective. Pediatrics, 124(3), S163-S175. doi:10.1542/peds.2009-1100d

Campbell, J. A., Walker, R. J., \& Egede, L. E. (2016). Associations between adverse childhood experiences, high-risk behaviors, and morbidity in adulthood. American Journal of Preventive Medicine, 50(3), 344-352. doi:10.1016/ j.amepre.2015.07.022

Cavanaugh, C. E., Petras, H., \& Martins, S. S. (2015). Genderspecific profiles of adverse childhood experiences, past year mental and substance use disorders, and their associations among a national sample of adults in the United States. Social Psychiatry and Psychiatric Epidemiology, 50(8), $1257-$ 1266.

Centers for Disease Control and Prevention. (2018). About Adverse Childhood Experiences (ACEs). Retrieved from CDC website: https://www.cdc.gov

Chapman, D. P., Whitfield, C. L., Felitti, V. J., Dube, S. R., Edwards, V. J., \& Anda, R. F. (2004). Adverse childhood experiences and the risk of depressive disorders in adulthood. Journal of Affective Disorders, 82(2), 217-225. doi:10.1016/j.jad.2003.12.013

Chen, E., \& Miller, G. E. (2014). Early-life socioeonomic status, emotion regulation, and the biological mechanisms of disease across the lifespan. In J. J. Gross (Ed.), Handbook of emotion regulation (2nd ed.) (pp. 586-595). New York: The Guilford Press

Dong, M., Dube, S. R., Felitti, V. J., Giles, W. H., \& Anda, R. F.
(2003). Adverse childhood experiences and self-reported liver disease: New insights into the causal pathway. Archives of Internal Medicine, 163(16), 1949-1956. doi:10.1001/ archinte.163.16.1949

Dube, S. R., Anda, R. F., Felitti, V. J., Croft, J. B., Edwards, V. J., \& Giles, W. H. (2001). Growing up with parental alcohol abuse: Exposure to childhood abuse, neglect, and household dysfunction. Child Abuse \& Neglect, 25(12), 1627-1640. doi:10.1016/s0145-2134(01)00293-9

Dube, S. R., Miller, J. W., Brown, D. W., Giles, W. H., Felitti, V. J., Dong, M., \& Anda, R. F. (2006). Adverse childhood experiences and the association with ever using alcohol and initiating alcohol use during adolescence. Journal of Adolescent Health, 38(4), 444.e1-10. doi:10.1016/ j.jadohealth.2005.06.006

Edwards, V. J., Holden, G. W., Felitti, V. J., \& Anda, R. F. (2003). Relationship between multiple forms of childhood maltreatment and adult mental health in community respondents: Results from the adverse childhood experiences study. American Journal of Psychiatry, 16(8), 1453-1460. doi:10.1176/appi.ajp.160.8.1453

Felitti, V. J., Anda, R. F., Nordenberg, D., Williamson, D. F., Spitz, A. M., Edwards, V., . . Marks, J. S. (1998). Relationship of childhood abuse and household dysfunction to many of the leading causes of death in adults: The Adverse Childhood Experiences (ACE) study. American Journal of Preventive Medicine, 14(4), 245-258. doi:10.1016/S07493797(98)00017-8

Felitti, V. J. (2002). The relationship of adverse childhood experiences to adult health: Turning gold into lead. Zeitschrift für Psychosomatische Medizin und Psychotherapie, 48(4), 359-369. doi:10.13109/zptm.2002.48.4.359

Finkelhor, D., Shattuck, A., Turner, H., \& Hamby, S. (2013). Improving the adverse childhood experiences study scale. JAMA pediatrics, 167(1), 70-75. doi:10.1001/ jamapediatrics.2013.420

Ford, K., Butler, N., Hughes, K., Quigg, Z., \& Bellis, M. A. (2016). Adverse Childhood Experiences (ACEs) in Hertfordshire, Luton and Northamptonshire. Liverpool, UK: Centre for Public Health.

Gallo, L. C., \& Matthews, K. A. (2003). Understanding the association between socioeconomic status and physical health: Do negative emotions play a role? Psychological Bulletin, 129(1), 10-51. doi:10.1037//0033-2909.129.1.10

Glowa, P. T., Olson, A. L., \& Johnson, D. J. (2016). Screening for adverse childhood experiences in a family medicine setting: A feasibility study. Journal of the American Board of Family Medicine, 29(3), 303-307. doi:10.3122/ jabfm.2016.03.150310

Gotlib, I. H., \& Hammen, C. L. (2009). Handbook of depression 
(2nd ed.). New York: Guilford Press

Gratz, K. L., \& Roemer, L. (2004). Multidimensional assessment of emotional regulation and dysregulation: Development, factor structure, and initial validation of the difficulties in emotion regulation scale. Journal of Psychopathology and Behavioral Assessment, 26(1), 41-54. doi:10.1023/ b:joba.0000007455.08539.94

Gunnar, M. R., \& Quevedo, K. (2007). The neurobiology of stress and development. Annual Review of Psychology, 58, 145173. doi:10.1146/annurev.psych.58.110405.085605

Harter, S. (1998). The effects of child abuse on the self-system. Journal of Aggression, Maltreatment \& Trauma, 2(1), 147169. doi: 10.1300/j146v02n01_09

Holt, M. K., Felix, E., Grimm, R., Nylund-Gibson, K., Green, J. G., Poteat, V. P., \& Zhang, C. (2017). A latent class analysis of past victimization exposures as predictors of college mental health. Psychology of Violence, 7(4), 521-532. doi: $10.1037 /$ vio0000068

Hughes, K., Bellis, M. A., Hardcastle, K. A., Sethi, D., Butchart, A., Mikton, C., . . . Dunne, M. P. (2017). The effect of multiple adverse childhood experiences on health: A systematic review and meta-analysis. The Lancet Public Health, 2(8), e356-e366. doi:10.1016/s24682667(17)30118-4

Kim, J., \& Cicchetti, D. (2006). Longitudinal trajectories of self-system processes and depressive symptoms among maltreated and nonmaltreated children. Child Development, 77(3), 624-639. doi:10.1111/j.1467-8624.2006.00894.x

Kroenke, K., Spitzer, R. L., \& Williams, J. B. W. (2001). The PHQ-9: Validity of a brief depression severity measure. Journal of General Internal Medicine, 16(9), 606-613. doi:10.1046/j.1525-1497.2001.016009606.x

Lo, Y., Mendell, N. R., \& Rubin, D. B. (2001). Testing the number of components in a normal mixture. Biometrika, 88(3), 767-778. doi:10.1093/biomet/88.3.767

Lubke, G., \& Muthén, B. O. (2007). Performance of factor mixture models as a function of model size, covariate effects, and class-specific parameters. Structural Equation Modeling: A Multidisciplinary Journal, 14(1), 26-47. doi:10.1207/s15328007sem1401_2

McLachlan, G., \& Peel, D. (2000). Finite mixture models. New York: Wiley.

Menard, C. B., Bandeen-Roche, K. J., \& Chilcoat, H. D. (2004). Epidemiology of multiple childhood traumatic events: Child abuse, parental psychopathology, and other familylevel stressors. Social Psychiatry and Psychiatric Epidemiology, 39(11), 857-865. doi:10.1007/s00127-004-0868-8

Merians, A. N., Baker, M. R., Frazier, P., \& Lust, K. (in press). Outcomes related to adverse childhood experience in college students: Comparing latent class analysis and cumulative risk. Child Abuse \& Neglect, in press. doi:10.1016/j.chiabu.2018.07.020

Merrick, M. T., Ports, K. A., Ford, D. C., Afifi, T. O., Gershoff, E. T., \& Grogan-Kaylor, A. (2017). Unpacking the impact of adverse childhood experiences on adult mental health. Child Abuse \& Neglect, 69, 10-19. doi:10.1016/ j.chiabu.2017.03.016

Mersky, J. P., Topitzes, J., \& Reynolds, A. J. (2013). Impacts of adverse childhood experiences on health, mental health, and substance use in early adulthood: A cohort study of an urban, minority sample in the U.S. Child Abuse \& Neglect, 37(11), 917-925. doi:10.1016/j.chiabu.2013.07.011

Mplus (Version 4.21). [Computer software]. Los Angeles, CA: Muthén \& Muthén.

Murray, S. L., Rose, P., Bellavia, G. M., Holmens, J. G., \& Kusche, A. G. (2002). When rejection stings: How selfesteem constrains relationship-enhancement processes. Journal of Personality and Social Psychology, 83(3), 556-573. doi:10.1037//0022-3514.83.3.556

Nagin, D. S. (2005). Group-based modeling of development. Cambridge, MA: Harvard University Press

National Survey of Child and Adolescent Well-Being. (2018). Research brief: Findings from the NSCAW study (Report No. 2018-020). Retrieved from ACF website: https://www.acf. hhs.gov

Nylund, K. L., Asparouhov, T., \& Muthén, B. O. (2007). Deciding on the number of classes in latent class analysis and growth mixture modeling: A monte Carlo simulation study. Structural Equation Modeling: A Multidisciplinary Journal, 14(4), 535-569. doi:10.1080/10705510701575396

Park, A., \& Kim, Y. (2018). The longitudinal influence of child maltreatment on child obesity in South Korea: The mediating effects of low self-esteem and depressive symptoms. Children and Youth Services Review, 87, 34-40 doi:10.1016/j.childyouth.2018.02.012

Pollack, S. D., \& Sinha, P. (2002). Effects of early experience on children's recognition of facial displays of emotion. Developmental Psychology, 38(5), 784-791. doi:10.1037/0012-1649.38.5.784

Ramiro, L. S., Madrid, B. J., \& Brown, D. W. (2010). Adverse Childhood Experiences (ACE) and health-risk behaviors among adults in a developing country setting. Child Abuse \& Neglect, 34(11), 842-855. doi:10.1016/ j.chiabu.2010.02.012

Roberts, J. E., Kassel, J. D., \& Gotlib, I. H. (1995). Level and stability of self-esteem as predictors of depressive symptoms. Personality and Individual Differences, 19(2), 217-224. doi:10.1016/0191-8869(95)00049-c

Roos, L. E., Afifi, T. O., Martin, C. G., Pietrzak, R. H., Tsai, J., \& Sareen, J. (2016). Linking typologies of childhood 
adversity to adult incarceration: Findings from a nationally representative sample. American Journal of Orthopsychiatry, 86(5), 584-593. doi:10.1037/ort0000144

Ryff, C. D. (1989). Happiness is everything, or is it? Explorations on the meaning of psychological well-being. Journal of Personality and Social Psychology, 57(6), 1069-1081. doi:10.1037//0022-3514.57.6.1069

Sack, V., \& Murphey, D. (2018). The prevalence of adverse childhood experiences, nationally, by state, and by race or ethnicity. Child Trends. Retrieved February 20, 2018 from https://www.childtrends.org/publications/prevalenceadverse-childhood-experiences-nationally-state-raceethnicity

Shin, S. H., McDonald, S. E., \& Conley, D. (2018). Patterns of adverse childhood experiences and substance use among young adults. Addictive Behaviors, 78, 187-192. doi:10.1016/j.addbeh.2017.11.020

The Child Health Data. (2016). ACEs resource packet: Adverse Childhood Experiences (ACEs) Basics. Retrieved from http://childhealthdata.org/docs/default-source/cahmi/acesresource-packet_all-pages_12_06-16112336f3c0266255aa b2ff00001023b1.pdf?sfvrsn=2

Turner, H. A., Finkelhor, D., \& Ormrod, R. (2010). Polyvictimization in a national sample of children and youth. American Journal of Preventive Medicine, 38(3), 323-330. doi:10.1016/j.amepre.2009.11.012

World Health Organization. (2009). Addressing adverse childhood experiences to improve public health: Expert consultation, 4-5 May 2009 (Meeting Report). Retrieved from WHO website: http://www.who.int

Xiao, Q., Dong, M.-X., Yao, J., Li, W.-X., \& Ye, D.-Q. (2008). Parental alcoholism, adverse childhood experiences, and later risk of personal alcohol abuse among Chinese medical students. Biomedical and Environmental Sciences, 21(5), 411-419. doi:10.1016/s0895-3988(08)60062-8

\section{In Korean}

Hong, C. Y., \& Kim, J. M. (2017) The effect of college students' interpersonal traumatic experiences on their emotional dysregulation: Mediating effect of self-system traumatization. Journal of Emotional \& Behavioral Disorders, 33(4), 333-353.

Hwang, I. H., \& Oh, D. H. (2014). Questionnaires for assessing stress and mental health. Hanyang Medical Reviews, 34(2), 91-95. doi:10.7599/hmr.2014.34.2.91

Jung, J. W. (2014). The effects of negative life events in preadulthood on adulthood depression: Mediator effect of interpersonal maladjustment. Korean Journal of Human Ecology, 23(6), 999-1012.
Jung, S. Y. (2012). The effects of child maltreatment on children's overweight and obesity problems-using children's emotional and behavioral problems as the mediator. Journal of the Korean Society of Child Welfare, 37, 37-68.

Kim, J., You, J.-W., \& Song, I. H. (2015). Effects of socioeconomic deprivation on depressive mood: Analysis of the moderating effect of age. Health and Social Welfare Review, 35(3), 4270.

Kim, J. W., Lee, B. C., Kang, T.-C., \& Choi, I.-G. (2013). The current situation of treatment systems for alcoholism in Korea. Journal of Korean Medical Science, 28(2), 181-189. doi:10.3346/jkms.2013.28.2.181

Kim, J. Y., Song, A. Y., \& Han, S. (2010). An overlapping experience of domestic violence and children's depression and delinquent behaviors. Korean Journal of Youth Studies, 17(12), 1-26.

Kim, M.-J., \& Yeum, D. M. (2012). A meta-analysis for how the child abuse experience effect on the child's school adaptation. Journal of Community Welfare, 43, 409-430. doi:10.15300/jcw.2012.12.43.409

Kim, S., \& Kim, D.-S. (2017). The relationship between trajectories of child maltreatment and adolescent suicidal ideation. Korean Journal of Child Studies, 38(2), 81-91. doi:10.5723/kjcs.2017.38.2.81

Kim, S., \& Lee, B. J. (2010). Latent profiles analysis of child maltreatment and adjustment. The Korean Journal of the Human Development, 17(1), 173-189.

Kim, S. J., \& Chung, I. J. (2013). A longitudinal study of persistent and recency effects of child maltreatment on depression-anxiety and aggression. Journal of Korean Society of Child Welfare, 43, 1-28.

Kim, S. W., Kim, J. B., Moon, Y. G., \& Shin, S. B. (2013). Korean General Social Survey, 2012 [Data file and code book]. Retrieved from https://kossda.snu.ac.kr/ handle/20.500.12236/15420

Lee, M. H., \& Kim, Y. H. (2017). Adverse childhood experience and depressive symptoms among male and female college students: The mediating role of self-esteem. Journal of Korean Council for Children \& Right, 21(2), 119-134. doi:10.21459/kccr.2017.21.2.119

Lee, M.-Y., \& Nam, M.-H. (2014). Interpersonal relationship and the influencing factors in nursing students. Journal of Digital Convergence, 12(6), 509-517. doi:10.14400/ jdc.2014.12.6.509

Oh, E., Noh, S., \& Cho, Y. (2009). The influences of negative social self-concept and difficulties in emotion regulation on social anxiety among university students. Cognitive Behavior Therapy in Korea, 9(1), 75-89.

Park, A. (2014). The effect of perceived neglect on children's depressive symptoms: Focusing on mediating effects of self- 
esteem and social withdrawal. Journal of Adolescent Welfare, 16(4), 397-416.

Ryu, J. H., Lee, J., Jung, I., Song, A., \& Lee, M. (2017). Understanding connections among abuse and violence in the life course (Report No. 2017-49). Sejong: Korea Institute for Health and Social Affairs.

Song, R., \& Lee, M.-A. (2016). Traumatic experiences in childhood and depressive symptoms in adulthood: The effects of social relationships. Korea Journal of Population Studies, 39(2), 1-24.

Yoon, H. (1997). The impact of child abuse and neglect on childparent relationship and self-esteem perceived by children. Journal of The Korean Society of Child Welfare, 12, 95-120.
Aely Park http://orcid.org/0000-0002-1580-6627

Ick-Joong Chung http://orcid.org/0000-0002-3426-7956

Received October 30, 2018

Revision received December 8, 2018

Accepted December 11, 2018 